\title{
As novas situações propostas de Pais e filhos em São Paulo: a tradução da poética originária de Stanislavski no contexto nacional
}

The new proposed circumstances of Fathers and sons in São Paulo the translation of Stanislavski's originary poetics in national context

\section{Lucia Regina Vieira Romano}

Lucia Regina Vieira Romano Atriz e pesquisadora, mestre em Comunicação e Semiótica pela Pontifícia Universidade Católica de São Paulo (PUC-SP) e doutora em Artes Cênicas pela Escola de Comunicações e Artes da USP (ECA-USP). Docente no Instituto de Artes da Universidade Estadual Paulista "Julio de Mesquita Filho" (DACEFC-Unesp). Atua na Cia Livre de

Teatro, sediada em São Paulo

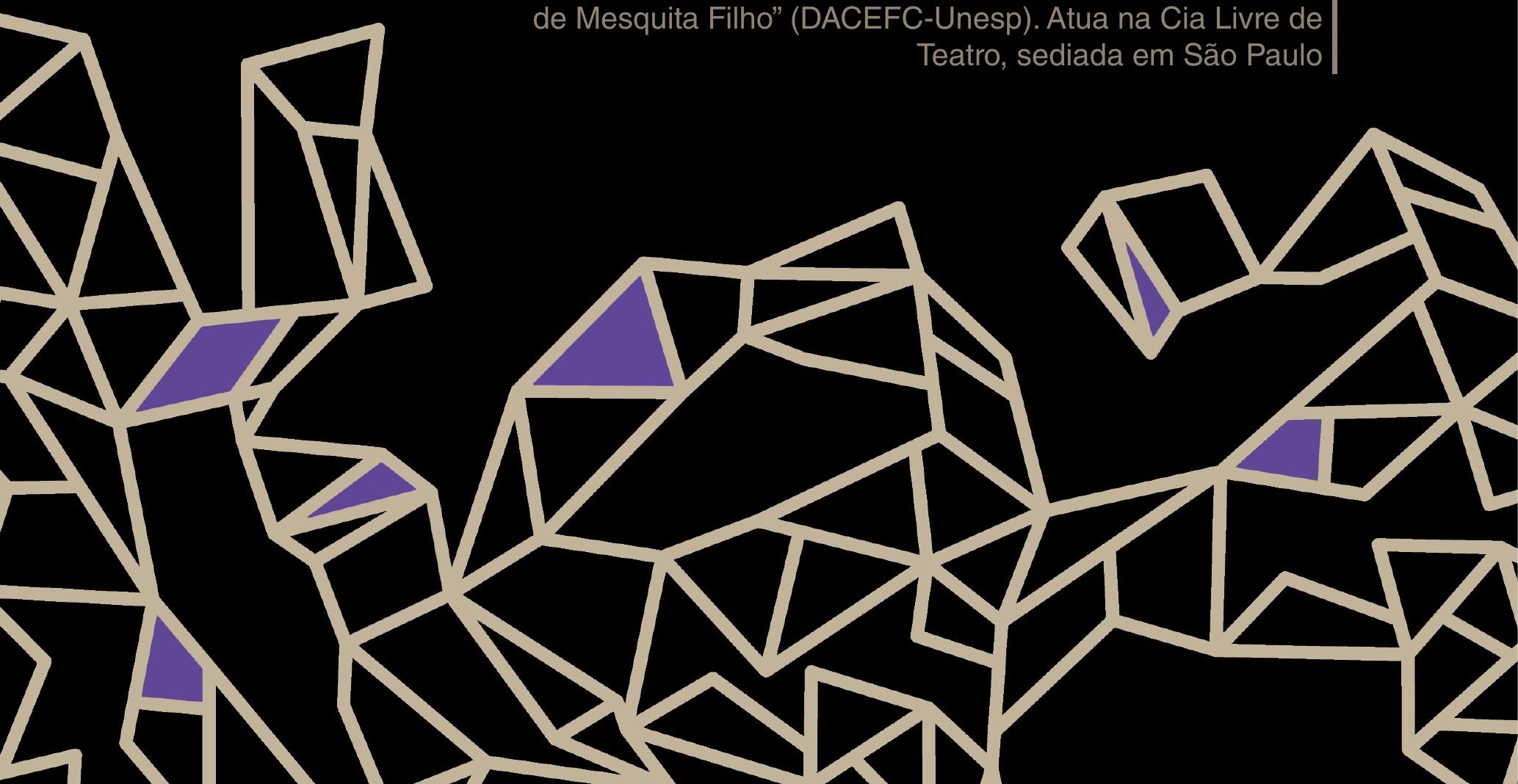




\section{Resumo}

Para pensarmos a herança de Stanislavski e sua poética atoral no contexto nacional, proponho um diálogo com a experiência da montagem de Pais e filhos, dirigida pelo encenador Adolf Shapiro, em São Paulo. Inspirada pelo encontro criativo entre a mundana companhia e Shapiro (e por meio dele, com a tradição teatral desenhada por Stanislavski), pretendo - emprestando termos da abordagem antropológica - relacionar a experiência dos atores e atrizes brasileiros no trabalho com o sistema a um processo de interculturação de tradições e técnicas, com a finalidade de refletir sobre as implicações dos horizontes geográficos e das demarcações histórico-temporais na transformação de matrizes atorais originárias. Palavras-chave: Teoria atoral, Teatro contemporâneo, Interculturalismo, Sistema Stanislavski.

\section{Abstract}

For us to think about Stanislavski's legacy and his poetics of acting in national context, I propose a dialogue with the experience of the production of Fathers and Sons, directed by Adolf Shapiro in São Paulo. Inspired by the creative encounter between mundana companhia and Shapiro (and by him, with the theatrical tradition drawn by Stanislavski), I intend - borrowing terms from the anthropological approach - to relate the experience of Brazilian actors and actresses working with the system to a process of interculturation of traditions and techniques, to reflect on the implications of geographical horizons and historical and temporal boundaries for the transformation of the original acting matrices.

Keywords: Theory of acting, Contemporary theater, Interculturalism, Stanislavski system.

\section{O sistema Stanislavski e suas interpretações}

A experiência da mundana companhia com o encenador russo Adolf Shapiro no projeto Pais e filhos, iniciado em maio de 2011', insere-se no diálo-

1 O espetáculo esteve em cartaz até novembro de 2012. Em 2013, foi lançada uma publicação sobre a montagem, o "Caderno de atuação - diário de montagem de Pais e filhos, nas manhãs, tardes e noites de 18 de maio de 2011 a 29 de setembro de 2012", financiado pela Lei de Fomento ao Teatro da Cidade de São Paulo e pelo Instituto Cultural Capobianco. 
go histórico da obra de Stanislavski com a cultura teatral nacional. O estabelecimento do sistema Stanislavski no teatro brasileiro poderia ser caracterizado como um trabalho lento de adaptação e decifração de uma matriz originária; num processo que remonta aos anos $1950^{2}$ e vem se desenvolvendo em "ondas", sucessivos fluxos e refluxos, que variam segundo as características da localidade observada e da década dos séculos $\mathrm{XX}$ e XXI a que nos referirmos. Se pensado na forma de um modelo intercultural, esse processo de adaptação e decifração poderia ser resumido por uma etapa inicial de introdução de novas normas, que se segue, aos poucos, pela imposição da "expertise" dessas normas e, conjuntamente, de seu "poder" sobre uma tradição interpretativa pré-existente. Se considerarmos as variáveis indicadas acima, todo o processo se torna mais complexo e interessante.

O código metodológico (PAVIS, 2011) trazido ao Brasil pelos divulgadores da tradição russa stanislavskiana levou à aquisição de esquemas de pensamento, que permitiram a incorporação de informações e de hábitos. Tendo em vista as limitadas análises sobre a "genética" da interpretação brasileira, é difícil afirmar o que a introdução desses novos modelos causou em termos da superação de outras culturas (ou reservas de memória) nacionais; por exemplo, aquelas baseadas na escola europeia ("adquiridas" via companhias francesas e portuguesas e o ensino formal ${ }^{3}$ ) e nas formas teatrais populares entre elas, o teatro de revista, o chamado teatro de variedades e o circo-teatro. De fato, a questão é enganadora, uma vez que a própria cultura teatral resulta de experiências, regras e práticas altamente plásticas e abertas à toda sorte de contaminações.

Desse modo, seria pouco produtivo tratarmos da relação entre as tradições interpretativas brasileira e russa numa oposição simples entre "fonte/origem" e "alvo". Tampouco, entre centro (a Rússia) e periferia (o Brasil). Entretanto, vale a pena lançar luz sobre a inevitável distorção de perspectivas presente nessa troca intercultural, que se estabelece sempre numa via de mão dupla.

2 Eugênio Kusnet ingressa no TBC em 1951 e no Teatro de Arena em 1958. Publica Iniciação à arte dramática em 1968, Introdução ao método da ação consciente, em 1971 e Ator e método, em 1975. Martim Gonçalves, diretor do grupo "A Barca" e criador da Escola de Teatro da UFBA, contudo, ensinava o método do Actor's Studio em torno de 1956.

3 Para Azevedo (2006), a primeira escola de teatro brasileira funcionou em São Paulo, a partir de 1906, seguindo o modelo do Conservatoire, de Paris. 
Em outras palavras: ao tratar da inserção de qualquer técnica de atuação na cultura teatral brasileira, como é o caso do sistema Stanislavski, é preciso olhar mais de perto as consequências residuais e assimetrias ali contidas.

\section{Os elementos de "abertura" do sistema}

O que parece marcante no caso da absorção do sistema Stanislavski no Brasil é a maneira como suas convenções, modelos e codificações foram bem-sucedidos, no sentido da sobrevivência de seus elementos na cena nacional. Arriscaria dizer que essa longevidade se dá ainda hoje em virtude de alguns aspectos da pesquisa stanislavskiana, relida, ininterruptamente, há pelo menos 100 anos $^{4}$, os quais apontam para o que se chamaria de "aberturas" ou porosidades do sistema. Seriam eles:

(1) A natureza prática que fundamenta a relação entre teorização e experimento, na qual a conceituação sintetiza a experiência e indica caminhos de retorno à artesania. Em Stanislavski, o privilégio da prática sobre a teoria encontra eco, por exemplo, na valorização da presentidade da "performance", em detrimento daquele modelo de "representação" herdado do século XIX. Derivam desse aspecto alguns procedimentos que buscam qualificar a presença viva do ator e da atriz, entre eles: (a) as técnicas de concentração, como o estado de solidão pública, o "viver"/ "to experience"; o trabalho de afetação a partir da evocação dos sentidos corporais, os círculos e objetos de atenção; (b) as técnicas de imaginação (visualização, o "se mágico"); (c) os procedimentos de trabalho sobre a comunicação (o subtexto, a irradiação, as improvisações verbal e silenciosa).

(2) Sua perspectiva pedagógica, que se relaciona ao engajamento na tarefa de tornar a prática da atuação cientificamente organizada. Tal objetivo levou Stanislavski não simplesmente a inventariar compulsivamente detalhes de suas descobertas, como também a inventar uma forma de transmissão eficiente de suas experiências. Seus livros, respondendo a esse anseio, utilizam um estilo que logra apresentar a construção da atuação em sua processualidade, muitas vezes errática. Mesmo as "adaptações" sofridas na versão dos

4 Para Gordon (1987), o sistema começou a ser "ensinado" em workshops no ano de 1911, ou seja, há 105 anos atrás. 
seus livros em inglês - que são as fontes mais usadas para as traduções em português - não eliminam a perspectiva múltipla, oferecida pelas diferentes personagens que dialogam, inseridas na experiência de aprendizado. Através dessas "vozes", Stanislavski destaca as ideias centrais do sistema e consegue retratar também a luta para compreendê-las (CARNICKE, 2000).

(3) O interesse no corpo em ação e nos aspectos psicofísicos do organismo, contradizendo dualismos fortemente arraigados, tais como natureza-cultura, corpo-mente, exterioridade-subjetividade. Ao lado da sua curiosidade pelas novas descobertas científicas (tais como da emoção encarnada, de Théodule Ribot), Stanislavski utilizou práticas corporais que enfatizavam o alinhamento entre corpo de carne, espírito e pensamento. Segundo Carnicke (2000), o processo de análise ativa, por entremear sucessivamente momentos de improvisação (da corrente de eventos, ações e contra-ações) e de análise intelectual, é um formato essencialmente holístico. Interessante notar que o investimento numa "ética orgânica" - que extrapola a "cultura do aprendizado técnico" e se espraia para a vida do ator e da atriz - distancia o emprego do sistema da massificação, ainda que atraente à máxima multiplicação.

(4) A visão do teatro como um fenômeno relacional. O sistema não diz respeito apenas ao cultivo da imaginação criadora pelo ator e pela atriz, ou à encarnação do papel, mas à relação entre as funções de atuação e direção. Ou seja, existe uma "dialética de tradução de perspectivas" na própria gênese do sistema. Além disso, Stanislavski atribui ao ator/atriz a possibilidade de efetuar suas próprias escolhas, quando confrontado com a alteridade. Essa preocupação embasa a coexistência de alguns expedientes, por exemplo, da análise "de mesa" somada à construção de visualizações - no processo de "cognição afetiva", o texto teatral e suas circunstâncias, explorados através da partitura de ações, o superobjetivo da encenação em contraste com o superobjetivo do ator/atriz etc.

(5) A compreensão do encenador acerca da natureza mista do processo teatral. Para o diretor russo, a obra artística é também produto cultural, ou em outras palavras, o teatro e o trabalho atoral estão situados no tripé produção-difusão-recepção, razão pela qual a transformação dos meios tecnológicos através dos anos não eliminou a aplicabilidade dos seus princípios sobre a atuação, mesmo que tenham sido nascidos no bojo do teatro. 
(6) Sua perspectiva de reinvenção pela "inscrição da atividade moderna" na tradição, acompanhando seu impacto, a qual hoje poderia ser lida como uma atitude pós-moderna.

(7) A recusa de Stanislavski ao tradicionalmente estabelecido. Em termos da herança teatral que o antecedia, o mestre russo procurou garantir um espaço autônomo para sua prática e pensamento sobre o teatro. No que tange à estruturação de um modelo/método para o futuro, para as gerações que o sucederiam, também recusa a tarefa de se manter num único caminho, deixando claro que a mera reprodução de procedimentos, por parte de seus continuadores, significaria estagnação - ainda que seu sistema ofereça uma coerência interna entre seus fragmentos, na maneira como se enunciam e se entremeiam.

(8) A ênfase na plasticidade e na capacidade de reajuste frente ao acontecimento teatral, pressuposta em conceitos, tais como "adaptação." Uma vez que o contato entre os intérpretes (e desses com os espectadores) é um dos objetivos centrais do momento da apresentação, a estratégia da adaptação aos elementos do aqui/agora do evento teatral (em especial, aos outros atores e atrizes em cena) deveria prevalecer sobre outros aspectos a ela anteriores, que não priorizam o objetivo de "chamar a atenção" de todos os envolvidos para o próprio ato de comunicação teatral.

A organicidade das ações físicas, por exemplo, depende tanto da adaptação quanto da percepção e da imaginação, sendo que a primeira coroa o processo criador deflagrado pelas demais. "Viver no momento" é a lei que determina que toda ação deve ser uma reação: é o princípio da adaptação que torna vivos os outros elementos, tais como os objetivos da cena e da personagem. Da mesma forma que a adaptação acontece na vida ordinária (somos diferentes de dia e de noite e, segundo o mestre russo, mudamos quem somos e como agimos quando estamos em outros países), na cena, ela deve reger a presença dos atores e atrizes, construindo uma teia de interações.

(9) A atitude humanista, que ilumina o trato sobre a cena. Essa postura pode ser entendida como uma vocação intercultural (mas não internacional, ou globalizada), na medida em que busca estabelecer um termo comum a todos os homens e mulheres, a partir de certa idealidade da natureza humana. 
(10) O momento histórico de formação de Stanislavski e de maturação do sistema, na Rússia e no Brasil. Nascido em fins do século XIX e trabalhando intensamente ao longo do século XX, o diretor russo acompanhou grandes transformações sociais, políticas e culturais, forjando uma compreensão acurada (ainda que dolorida!) das contradições de seu tempo e dos cruzamentos entre arte, política e sociedade.

Por outro lado, considerando a "introdução" do sistema no Brasil, é possível notar que variados aspectos da cultura teatral nacional colaboraram para que as propostas de cultivo da ciência da atuação, ao lado da profissionalização dos atores e atrizes, frutificassem nessas margens do Oceano Atlântico. Foi um condicionante local importante a existência de companhias teatrais preocupadas com o surgimento de uma nova interpretação, diversa dos modelos do "ator vedete" e das companhias familiares. A presença dessas novas companhias correspondia, em termos mais amplos, a um maior desenvolvimento da economia das artes cênicas, ao mesmo tempo em que há uma fome por referências sobre atuação "chanceladas" pela cultura teatral erudita (diga-se, europeia e estadunidense).

A entrada nos palcos nacionais de uma dramaturgia menos dependente dos "tipos" e baseada em personagens mais desenhados em termos psicológicos, também se conjugou aos outros aspectos. A partir dos anos 50 , quando o contexto sociopolítico inspirava a procura pelo retrato da realidade do homem brasileiro nos palcos, a possibilidade de utilização do sistema, para uma linguagem realista, serviu como uma luva. Interessante notar que a distância entre Stanislavski e Brecht, tão enfatizada em outros países, no Brasil não se deu tão fortemente naquele primeiro momento.

\section{Os elementos de "fechamento" do sistema}

Toda cultura, contrariamente às suas aberturas (ou, ao seu potencial interno de transformação), precisa estabelecer contornos e, para isso, recusar em certa medida as invasões "exógenas". Quanto ao pensamento de Stanislavksi, alguns desses traços de fechamento são pontuais e circunstanciados. Pode-se afirmar que, observando o processo de criação teatral, bem como a abordagem do encenador russo para as técnicas de atuação e 
direção, os momentos de maior fechamento correspondem à aproximação da ocasião de estreia.

Para Stanislavski, ameaçado pela eminência do encontro com o espectador, o cultivo do mundo interno das personagens e da peça pode perder terreno. A chegada da estreia também traz para os ensaios uma quantidade considerável de distrações que podem interromper o fluxo da vivência dos atores e atrizes e até mesmo a escuta do diretor/a para a fisicalização das necessidades internas do elenco.

Outros "fechamentos" do sistema, não "previstos" em vida pelo mestre russo, são frutos da conjuntura histórica e da ação do tempo. Algumas dessas transformações valem um exame breve:

(1) Passados anos da organização de seus pressupostos criativos, Stanislavski já é mais do que uma "influência" na cultura teatral ocidental. Seu sistema - ainda que à revelia de seu autor - tornou-se mais do que um simples "manual de procedimentos" funcional. Contudo, quando o estado de "experiência em fluxo" é eliminado, o dogmatismo toma conta. Em muitos contextos, abraçado como um método estrito, ou uma solução programática, o sistema se institucionalizou, sofrendo uma inevitável simplificação. Consequentemente, a natureza fluida da criatividade, que seria o limite territorial do sistema, cede à repetição esvaziada de hábitos de atuação e tende a fenecer, perdendo seu núcleo vital.

(2) A trajetória política da Rússia, no período posterior à morte de Stanislavski, e a decorrente dificuldade de circulação das informações colaboraram para o silenciamento em torno das práticas tidas como menos dogmáticas e mais dependentes de ideias "abstratas", tais quais emotividade, descontrole, flutuação de sentido, espiritualidade etc. Em virtude dessa coerção oficial (realidade apenas hoje discutida com mais liberdade entre os estudiosos), para muitos dos atores e atrizes brasileiros, ainda hoje, o trabalho do encenador russo diz respeito apenas à construção da personagem no modelo de teatro de texto e de cunho realista.

(3) Também o tipo de coletividade que está envolvida no processo de trabalho sobre o sistema interfere em seus resultados. Stanislavski se dedicou a investigar a atuação, motivado pela busca de um novo intérprete, inserido 
numa coletividade de artistas. Seu foco não residia no ator-estrela, nem nos elencos rotativos do século XIX.

Na cena teatral paulistana, da qual faz parte a mundana companhia, os modos de criação em grupo estão fortemente inspirados no procedimento de criação em colaboração. Em linhas muito gerais, isso significa um grupo habituado com a convivência coletiva, com grande intimidade na criação de encenações, talvez, em detrimento de um mergulho mais aprofundado nas especificidades da artesania da interpretação, em especial, no aspecto da personagem dramática. Esse tipo de coletividade diverge do "grupo tradicional," do "elenco profissional" e, principalmente, da antiga relação entre atores e direção, sobre a qual Stanislavski dedicou sua atenção.

(4) Embora o contato com culturas estrangeiras tenha sido um aspecto presente na formação eclética de Stanislavski e, portanto, também expressa em seu sistema, a necessidade de dar relevo à abordagem dos fatores ideológicos, políticos e socioeconômicos presentes na cultura - e, consequentemente, do elemento sociocultural em vigor no comportamento individual - não foi um tema central de sua investigação. Mudanças mais amplas no contexto mundial tiveram que acontecer para que pensadores e praticantes do teatro mais próximos de nosso tempo buscassem destacar as condicionantes históricas da personagem (pensando em Bertolt Brecht), ou mesmo a interface entre treinamento atoral, linguagem cênica e tradição cultural (no caso do trabalho de Eugenio Barba).

Entrelaçando os aspectos diversos que procurei enfocar aqui, torna-se mais notável a série de operações e interferências interculturais que ocorrem quando um elenco de atores e atrizes brasileiros se encontra com um encenador russo para encenar um texto russo em terras tupiniquins e em língua portuguesa. A concorrência entre modelizações, sejam elas explicitas ou implícitas, se estabelecerá de imediato. Num efeito dominó, esse choque tenderá a se repetir para além da estreia, no embate com a realidade cotidiana dos espectadores (considerando ainda o tipo de informação sobre as linguagens teatrais que eles possuem). Desse modo, se levarmos em conta que o campo teatral guarda técnicas aculturadas de atuação inscritas nos corpos, na cena e fora dela, seria essencial concentrar maior atenção aos automatismos do 
hábito e às novidades que rompem os estereótipos dos códigos de atuação, em seus contextos locais.

Imagino que, a fim de atingir a complexidade do diálogo intercultural presente no tipo de cruzamento de fronteiras geográficas que as formas e técnicas artísticas conheceram no século XXI, tal qual o processo vivenciado na montagem paulista de Pais e filhos, além de se trabalhar a memória afetiva, fosse necessário experimentar procedimentos para a manipulação de uma espécie de memória cultural. Tendo em vista que Stanislavski definiu a importância do mergulho do elenco no universo da peça, apreciando, inclusive, elementos externos às circunstâncias do texto, mas apropriados ao autor, às personagens e/ou ao momento histórico no qual ocorrem os acontecimentos, é possível imaginar seu interesse pelas novas circunstâncias propostas nessa segunda década do novo século. Essa memória cultural seria também psicofísica, encarnada nas menores escolhas dos atores, atrizes, diretores e diretoras.

\section{A interpretação como um ato de tradução poética}

Para concluir esses pensamentos, proponho - adotando agora um conceito comum aos estudos da cultura - imaginarmos a "presença de Stanislavski” e suas propostas como um texto. Esse texto chega até nós distanciado de seu contexto original, carecendo de tradução para que o sentido dessa presença aflore, convocando não apenas a sua memória, mas a sua atualização. Atores e atrizes seriam os tradutores desse texto cultural, assim como são, na cena, tradutores de textualidades diversas.

Nós, atores e atrizes, assim como os diretores e diretoras, somos por natureza tradutores, transportamos mensagens. Nossa competência reside no estabelecimento da comunicação e, tal qual Hermes, ou Exu (para fazermos uma correspondência com uma personagem da mitologia afro-brasileira), vivemos na encruzilhada. Abrimos caminho, fraudamos ${ }^{5}$, persuadimos, criamos confusão ou entendimento, apresentamos oferendas e sacrifícios, conduzimos a carruagem do Deus (ou, somos nós mesmos a carruagem?). No campo das textualidades, sejam da cena ou da dramaturgia, o(a) intérpre-

$5 \mathrm{O}$ tradutor tende à neutralidade, mas precisa ser confiável, porque opera no terreno do contágio. 
te opera na recriação poética, buscando instrumentos precisos para ampliar a dimensão de significação de uma ação (e não para reduzi-la, ou explicar seu campo de afinidades).

No processo criativo, a dialética da troca é ainda mais central. Nele, a operação de tradução acontece em múltiplos níveis: na passagem entre códigos diversos (do texto escrito para o corpo, do corpo para o movimento no espaço, do movimento no espaço para o texto falado), no trânsito entre enquadramentos (do mundo "natural" para a personagem ficcional e desta para o aqui-agora da "performance"), no deslizamento entre experiências humanas situadas diversamente no tempo (do processo de ensaios para o período de apresentações), no intercâmbio entre processos de criação e produção de sentido (do/a autor/a, do/a diretor/a, do/a ator/atriz e do/a espectador/a) e assim por diante.

\section{Outras traduções, operadas no espaço e no tempo}

O que se converte, no caso da tradução do sistema e do próprio "texto Stanislavski”, não são as palavras. No sentido global, as mensagens é que são o objeto das tarefas de interpretação e substituição. Dessa forma, a presença do encenador russo no Brasil é composta não apenas de linhas e palavras, mas também de entonações, silêncios, vazios, nos quais a poesia da sua "fala" pode ser perseguida. A tarefa de compreendê-lo e reinterpretá-lo no Brasil é, portanto, marcada pelo processo de troca intercultural e de negociação.

A língua do "texto Stanislavski", cabe frisar, ainda que "disseminada", não é uma "língua franca" - cuja função seria banir aspectos políticos (e econômicos e militares) da dominação de uma língua, dita natural, sobre outra, com a finalidade de permitir o contato ${ }^{6}$. Seu universo sígnico e sua força vital divergem, portanto, das línguas que existem para contornar a realidade da diferença, como as línguas de sinais e o esperanto. Esses idiomas artificiais, construídos não pela lógica evolutiva de uma determinada comunidade étnica ou de um povo, apostam numa grande comunidade (muitas vezes transna-

6 A existência de uma variedade de formas linguísticas é um ato de resistência, delimitando territórios e identidades que vão além dos estados-nações. A língua permite a percepção da diferença e a autonomia de comunidades - usar a própria língua é, portanto, um direito. 
cional, como no caso do esperanto), forjando um território de neutralidade. Contrariamente, a tradução do sistema significa a presença do "mestre" e a participação criativa do tradutor, numa paridade que vai se constituindo na ação. Como diz Schechner (1982):

Troca intercultural necessita de um mestre, alguém que conhece o corpus do espetáculo da cultura sendo traduzida. $O$ tradutor da cultura [por sua vez] não é um simples agente, como um tradutor de palavras seria, mas um verdadeiro difusor cultural. Por isso é que atuar outras culturas se torna tão importante. Não apenas lendo-as, não apenas visitando-as, ou as importando - mas de fato as fazendo. De modo que "eles" e "nós" é omitido, ou posicionado, experiencialmente, lado a lado. (p. 3)7

Traduzir o idioma de Stanislavski é torná-lo vivo em outros contextos, encontrando um princípio de equivalência e não de identidade, ou seja, operar a apropriação de sua gramática e léxico numa dialética de transposição entre texto e contexto no universo da cultura e do teatro. Para dar esse passo, as artes cênicas nacionais precisam conhecer sua história íntima, pela perspectiva não apenas da dramaturgia ou da encenação, mas também da cultura atoral, ou seja, do desenvolvimento dos saberes dos atores, atrizes, diretores e diretoras, no contexto do teatro e da sociedade brasileiros.

Pelo exposto, a herança de Stanislavski pode ser entendida como um "conhece-te a ti mesmo": é uma proposta - como diria o ensaísta, tradutor e poeta Octavio Paz - de revisitação da experiência infantil de aprender palavras desconhecidas e, assim, ampliar a própria linguagem. Desse modo, o valor de seu legado não está em suas origens na Rússia de início do século XX, nem no Brasil do século XXI, mas num tempo-espaço em construção: ele renova continuamente a oportunidade de participação e de troca de saberes e afetos, por meio da prática atoral. Para melhor traduzir a poética de Stanislavski deve-se não apenas dizer suas palavras, mas fazê-las (MESCHONNIC, 1999), inscrevendo-se como sujeito dentro delas.

7 No original: "Intercultural Exchange takes a teacher: someone who knows the body of performance of the culture being translated. The translator of culture is note a mere agent, as a translator of words might be, but an actual culture-bearer. This is why performing other cultures becomes so important. Not just reading them, not just visiting them, or importing them - but actually doing them. So that "them" and "us" is elided, or laid experientially side-by-side". 


\section{Referências bibliográficas}

AZEVEDO, E. R. Conservatório Dramático e Musical de São Paulo: pioneiro e centenário. Histórica: revista on-line do Arquivo Público do Estado de São Paulo, São Paulo, ano 2, n. 16, p. 1-6, nov. 2006. Disponível em: <http://www.historica.arquivoestado.sp.gov.br/materias/anteriores/edicao16/materia01/texto01.pdf>. Acesso em: 2 jun. 2016.

CARNICKE, S. M. Stanislavsky's system: pathways for the actor. In: HODGE, A. (Ed.) Twentieth century actor training. London: Routledge, 2000.

GORDON, M. The Stanislavsky technique. Russia. New York: Applause Books, 1987.

MESCHONNIC, H. Poétique du traduire. Paris: Verdier, 1999.

PAVIS, P. A análise de espetáculos. São Paulo: Perspectiva, 2011.

PAZ, O. Tradução: literatura e literalidade. Tradução Doralice Alves de Queiroz. Belo Horizonte: FALE/UFMG. 2009. p. 8-32. Disponível em: <http://150.164.100.248/vivavoz/data1/arquivos/traducao2ed-site.pdf>. Acesso em: 2 jun. 2016.

$\mathrm{ROACH}, \mathrm{J}$. R. The player's passion: studies in the science of acting. Newark: University of Michigan Press; London: Associated University Presses, 1985.

ROMANO, L. et al. Caderno de atuação: diário de montagem de Pais e Filhos, nas manhãs, tardes e noites de 18 de maio de 2011 a 29 de setembro de 2012. São Paulo: Barca de Dionisos, 2013.

SCHECHNER, R. Intercultural performance: an introduction by guest editor Richard Schechner. The drama review, v. 26, n. 2, p. 3-4, 1982.

Recebido em 18/03/2016

Aprovado em 17/05/2016

Publicado em 01/07/2016 